\title{
Minimal change nephropathy associated with anaplastic carcinoma of bronchus
}

\author{
Charles R.J. Singer ${ }^{1}$ and J. Michael Boulton-Jones ${ }^{2}$ \\ ${ }^{1}$ Department of Haematology, School of Medicine, University College, London WC1E $6 H X$ and $^{2}$ Renal Unit, \\ Royal Infirmary, Glasgow G4 OSF, UK.
}

\begin{abstract}
Summary: Nephrotic syndrome associated with extra-renal malignancy shows a characteristic pattern: carcinoma is most frequently associated with membranous glomerulonephritis and Hodgkin's disease with minimal change nephropathy. We report a patient with minimal change nephropathy in association with anaplastic carcinoma of the bronchus. Strong temporal evidence of a causal relationship is presented. The dissociation in the response of the two conditions to treatment of the tumour after relapse may be evidence of an indirect pathogenesis.
\end{abstract}

\section{Introduction}

Malignancy is a rare but well recognized cause of the nephrotic syndrome which was first described by Galloway (1922). Various histopathological changes are described in the kidneys and these have been reviewed by Eagen \& Lewis (1977). Carcinoma is most frequently associated with membranous nephropathy and Hodgkin's disease with minimal change nephropathy (MCN). Lee et al. (1966) were the first to report a high incidence of carcinoma in patients presenting with the nephrotic syndrome: 11 of 104 nephrotic patients developed a carcinoma and 8 of those 11 had membranous nephropathy. The association was confirmed by Row et al. (1975) who found that 7 of 66 patients with membranous nephropathy also had occult carcinoma.

We present a patient who had a poorly differentiated carcinoma of the bronchus and $\mathrm{MCN}$. The clinical events support the hypothesis that the tumour caused the renal lesion.

\section{Case report}

A 46 year old woman presented with a 3 month history of tiredness, cough, mild exertional dyspnoea and facial and peripheral oedema. She had smoked 10 cigerettes per day until 2 years before. Proteinuria was detected by her general practitioner, but her oedema had not responded to diuretic therapy and peripheral oedema was present on admission.

Correspondence: C.R.J. Singer, B.Sc., M.B., Ch.B., M.R.C.P.

Accepted: 4 July 1985
Laboratory investigations showed normal full blood count, urea, creatinine and electrolytes. Serum albumin was $20 \mathrm{~g} / \mathrm{l}$ and selective proteinuria of $7.7 \mathrm{~g} /$ 24 hours was demonstrated. A percutaneous renal biopsy contained 25 glomeruli with normal light microscopic appearances and no deposits of immunoglobulins, complement or fibrinogen by immunofluorescence. Electron microscopy demonstrated epithelial cell foot process fusion, but no other abnormality and a diagnosis of minimal change nephropathy was made. The chest $\mathrm{X}$-ray revealed a left upper lobe opacity which was found to be due to an anaplastic bronchial carcinoma and a left upper lobectomy was performed.

The clinical course is summarized in Figure 1. Postoperative proteinuria of $12.8 \mathrm{~g}$ /day fell to $0.4 \mathrm{~g}$ /day 3 weeks later. By the seventh post-operative week diuretics were discontinued. No steroid or immunosuppressive therapy was administered. During the next 15 months neither oedema nor proteinuria was detected, the serum albumin was normal and there was no evidence of tumour recurrence.

Nineteen months after surgery, mild peripheral oedema was noted and proteinuria of $13.4 \mathrm{~g} /$ day discovered. A chest X-ray revealed a left paramediastinal mass and mediastinoscopy and biopsy confirmed local recurrence of the original tumour. Diuretic therapy was commenced and local radiotherapy (45 Gy in 20 fractions) administered for 3 weeks. Six pulses of chemotherapy were given at monthly intervals: cyclophosphamide $75 \mathrm{mg} / \mathrm{m}^{2}$ and vincristine $2 \mathrm{mg} / \mathrm{m}^{2}$ with 5-fluouracil $15 \mathrm{mg} / \mathrm{kg}$ on two occasions and with methotrexate $50 \mathrm{mg} / \mathrm{m}^{2}$ on four occasions, all intravenously. The oedema resolved after radioth- 

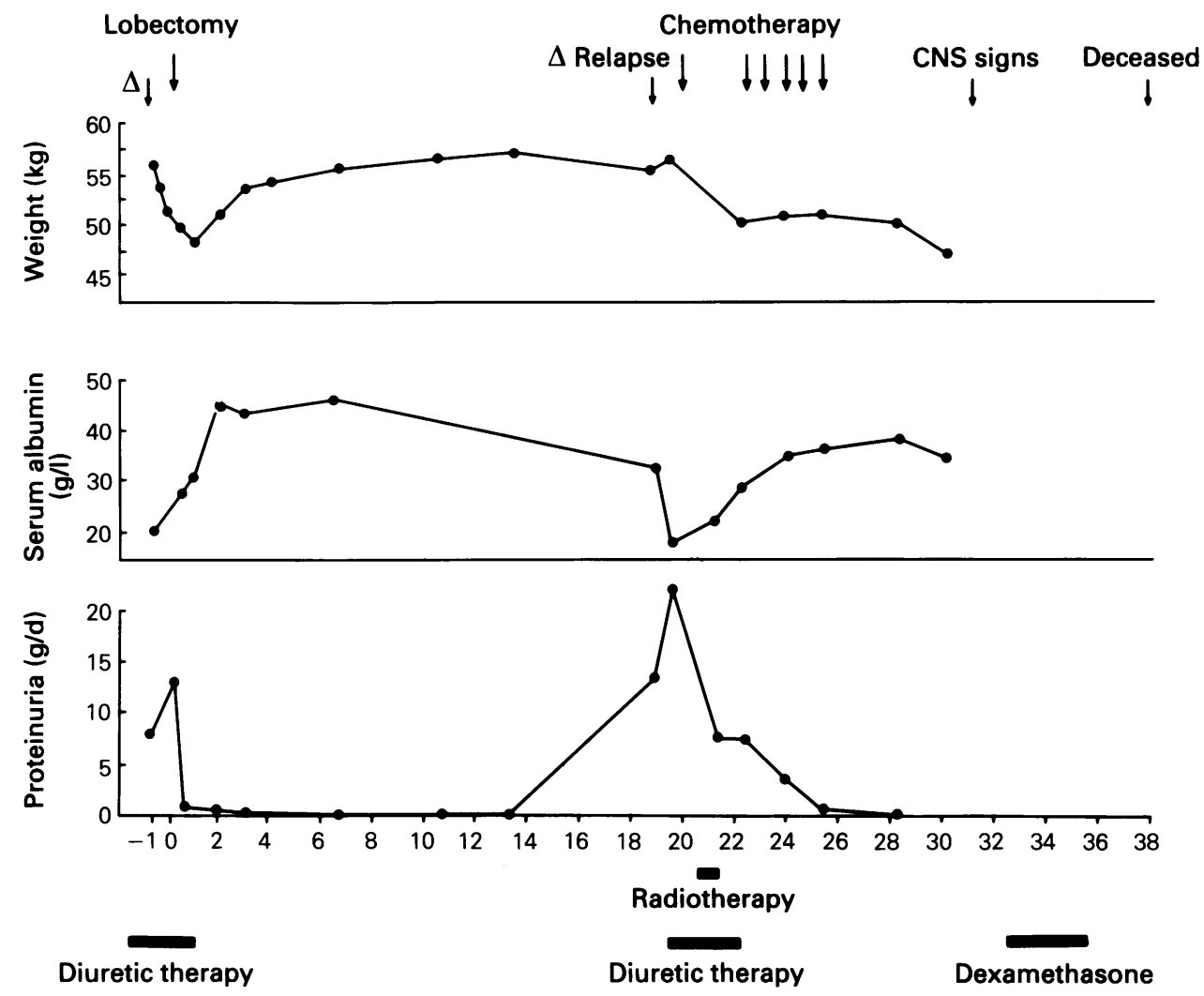

Time (months) after surgery

Figure 1 Summary of clinical course.

erapy and the proteinuria decreased over the following 3 months to $0.15 \mathrm{~g} /$ day. During this period the peripheral blood leucocyte count varied between 4.1 and $8.2 \times 10^{9} / 1$.

Despite resolution of the oedema, she remained unwell with continuing low levels of proteinuria. Persistence of tumour was detected on bronchoscopy. She subsequently developed a left hemiparesis and death occurred 3 years after initial presentation.

\section{Discussion}

The renal lesion in patients with nephrotic syndrome associated with carcinoma is most commonly membranous nephropathy. Eagen \& Lewis (1977) found this lesion in $69 \%$ of patients with nephrotic syndrome and carcinoma. No particular type of carcinoma predominated and survival after tumour diagnosis was short (median 3 months), few patients having remission of their nephrotic syndrome. Others have repor- ted that between 2 and $10 \%$ of patients with membranous nephropathy are subsequently found to have carcinoma (Row et al., 1975; Noel et al., 1979; Tu et al., 1984). A few patients with carcinoma in association with proliferative, crescentic and membranoproliferative glomerulonephritis have also been reported (Hopper et al., 1975; Tydings et al., 1978; Jermanovich et al., 1982).

Eagen \& Lewis cited three cases of MCN associated with carcinoma in their 1977 review. However, only two of these have been published (Lee et al., 1966; Richard-Mendes da Costa et al., 1974) and in only the former is there detailed clinical and pathological information. Though the renal biopsy of this patient was examined by electron microscopy, the absence of immunofluorescence studies in either patient fails to fully exclude early membranous nephropathy (Helin et al., 1980; Pascal et al., 1976). Three further patients have been reported (Moorthy, 1983; Forland \& Bannayan, 1983) and the details of all five patients are shown in Table I. Two patients with small cell carcin- 


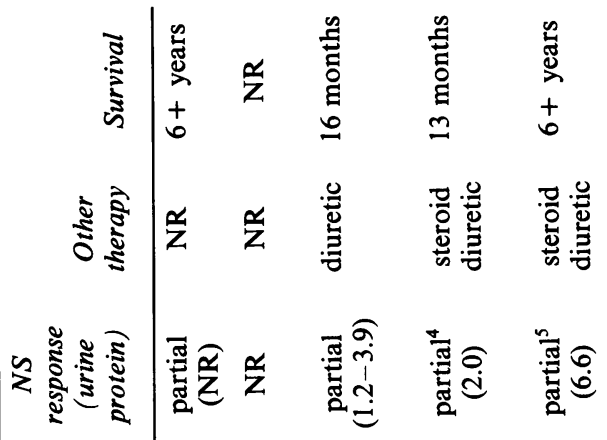

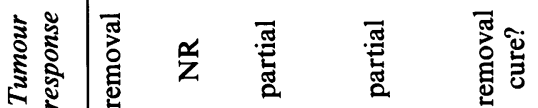

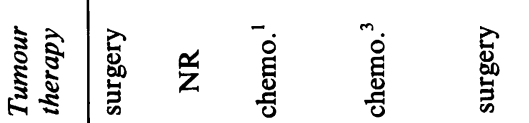

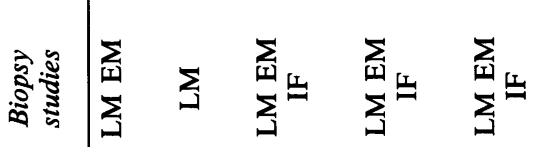

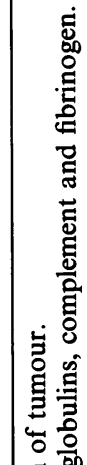

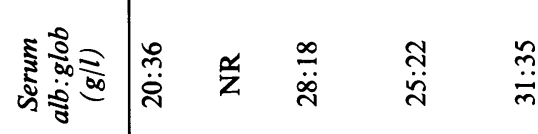

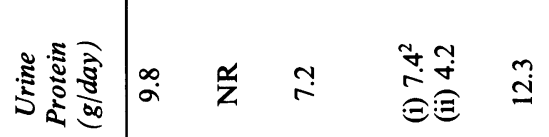

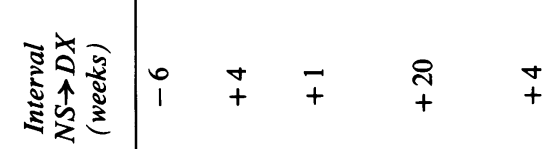

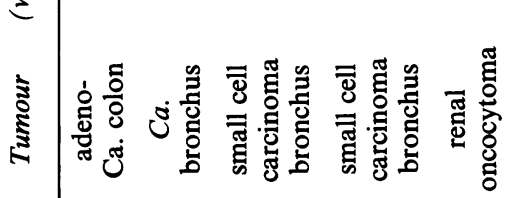

ڤัँ

额言

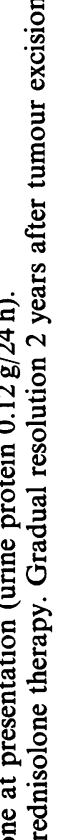

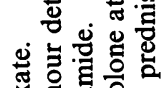

资总

ฐี

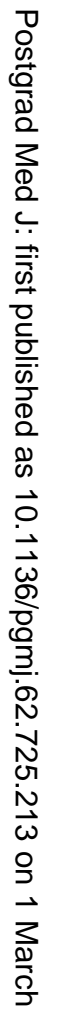

융

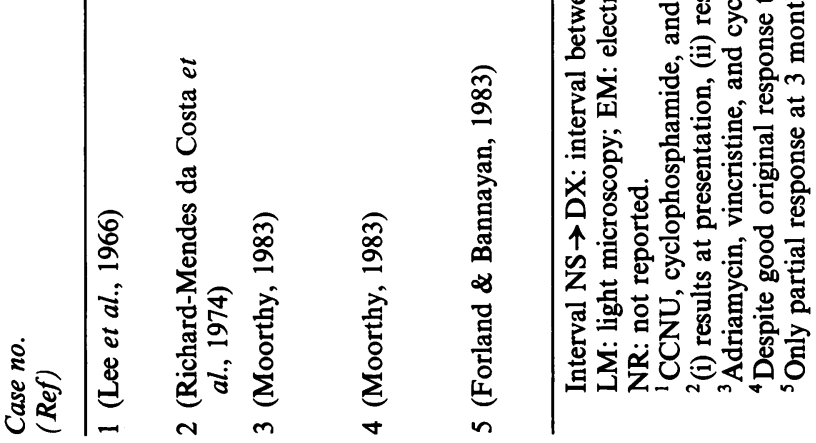


oma of bronchus showed partial tumour response and improvement in oedema following combination chemotherapy though significant proteinuria persisted until death.

Interestingly the nephrotic syndrome in patient 4 had responded dramatically to prednisolone prior to tumour detection, but subsequently relapsed. The patient of Forland \& Bannayan (1983) had only a minor improvement in his nephrotic syndrome following excision of the oncocytoma despite prednisolone therapy, though 2 years later complete resolution of his nephrotic syndrome occurred.

Deposition of immune complexes containing tumour associated and idiopathic $\mathrm{MCN}$ is, by contrast, obscure. Although Hodgkin's disease is the most cancer (Couser et al., 1974; Lewis et al., 1971; Wakashin et al., 1980; Weksler et al., 1974; Constanza et al., 1973) and the probable cause of proliferative lesions (Jermanovich et al., 1982). The pathogenesis of both tumour associated and idiopathic $\mathrm{MCN}$ is, by contrast, obscure. Although Hodgkin's disease is the most commonly associated malignancy (Gagliano et al., 1976), Plager \& Stutzman (1971) found that only 4 out of 600 patients $(0.65 \%)$ with Hodgkin's disease became nephrotic. However there is strong temporal evidence of a causal relationship. The diagnoses of nephrotic syndrome and Hodgkin's disease are often made at the same time and proteinuria remits only when the lymphoma is effectively treated and recurs when the tumour relapses (Plager \& Stutzman, 1971; Ghosh \& Muehrcke, 1970; Sherman et al., 1972). These and other observations led Shalhoub (1974) to

\section{References}

BOULTON-JONES, J.M. (1984). Tuberculosis and minimal change nephropathy. Scottish Medical Journal, 29, 114.

BOULTON-JONES, J.M. \& SIMPSON, S. (1980). Immunological studies of minimal change nephropathy. British Medical Journal, 280, 291.

BOULTON-JONES, J.M., TULLOCH, I., DORE, B. \& MCLAY, A. (1983). Changes in glomerular capillary wall induced by lymphocyte products and serum of nephrotic patients. Clinical Nephrology, 20, 72.

CONSTANZA, M.E., PINN, V., SCHWARTZ, R.S. \& NATHANSON, L. (1973). Carcinoembryonic antigen-antibody complexes in a patient with colonic carcinoma and nephrotic syndrome. New England Journal of Medicine, 289, 520.

COUSER, W.G. \& SALANT, D.J. (1980). In situ immune complex function in glomerular injury. Kidney International, 17, 1.

COUSER, W.G., WAGONFIELD, J.B., SPARGO, B.H. \& LEWIS, E.J. (1974). Glomerular deposition of tumour antigen in membranous nephropathy associated with colonic carcinoma. American Journal of Medicine, 57, 962.

EAGEN, J.M. \& LEWIS, E.J. (1977). Glomerulopathies of neoplasia. Kidney International, 11, 297.

FORLAND, M. \& BANNAYAN, G.A. (1983). Minimal change postulate that a soluble factor produced by lymphocytes was directly or indirectly toxic to the glomerular capillary and caused proteinuria. Some experimental support has been forthcoming (Lagrue $e t$ al., 1975; Boulton-Jones \& Simpson, 1980; BoultonJones et al., 1983), and relapses of MCN have been associated with pollen exposure (Reeves et al., 1975), tuberculosis (Boulton-Jones, 1984) and circulating immune complexes (Levinsky et al., 1978), all of which may stimulate lymphokine production.

The patient reported here had the same temporal relationship between proteinuria and tumour activity as described in Hodgkin's disease. A causal relationship seems likely and the clinical course may provide clues to the pathogenesis. Remission followed tumour resection more quickly and completely than in previously reported cases, though neither steroids nor cytotoxic drugs were administered. This initial response and the recurrence of proteinuria at the first sign of tumour recurrence are consistent with proteinuric factor production by or in response to the tumour. Moorthy (1983) postulated proteinuric factor production by the tumour in his two patients with small cell bronchial carcinoma, a tumour frequently associated with inappropriate hormone production. However, treatment of this patient's relapse by radiotherapy and chemotherapy led to remission of the proteinuria despite tumour progression. Although alternative explanations are possible, this dissociation may in dicate that the proteinuric factor was not produced by the tumour cell but by another chemosensitive cell such as the T-lymphocyte.

lesion nephrotic syndrome and renal osteocytoma. American Journal of Medicine, 75, 715.

GAGLIANO, R.G., COSTANZI, J.J., BEATHARD, G.A., SARLOW, H.E. \& BELL, J.D. (1976). The nephrotic syndrome associated with neoplasia: an unusual paraneoplastic syndrome. American Journal of Medicine, 60, 1026.

GALlOWAY, J. (1922). Remarks on Hodgkin's disease. British Medical Journal, 2, 1201.

GHOSH, L. \& MUEHRCKE, R.C. (1970). The nephrotic syndrome: a prodrome to lymphoma. Annals of Internal Medicine, 72, 379.

HELIN, H., PASTERNACK, A. \& HAKALA, T. (1980). Glomerular electron dense deposits and circulating immune complexes in patients with malignant tumours. Clinical Nephrology, 14, 23.

HOPPER, J., BIAVA, C.B. \& NAUGHTON, J.L. (1976) Glomerular extracapillary proliferations (crescentric glomerulonephritis) associated with non-renal malignancies. Kidney International, $10,544$.

LAGRUE, G., XHENEUMONT, S., BRANELLEL, A., HIRBEC, G. \& WEIL, B. (1975). A vascular permeability factor elaborated from lymphocytes. Demonstration in patients with nephrotic syndrome. Biomedicine, 23, 37. 
JERMANOVICH, N.B., GIAMMARCO, R., GINSBERG, S.J., TINSLEY, R.W. \& JONES, N.B. (1982). Small cell anaplastic carcinoma of the lung with mesangial proliferative glomerulonephritis. Archives of Internal Medicine, 142, 397.

LEE, J.C., YAMAUCHI, H. \& HOPPER, J. (1966). The association of cancer and the nephrotic syndrome. Annals of Internal Medicine, 64, 41 .

LEVINSKY, R.J., MALLEJON, P.N., BARRATT, T.M. \& SOOTHILL, J.F. (1978). Circulating immune complexes in steroid responsive nephrotic syndrome. New England Journal of Medicine, 298, 126.

LEWIS, M.G., LOUGHRIDGE, L.W. \& PHILLIPS, T.M. (1971). Immunological studies in nephrotic syndrome associated with extrarenal malignant disease. Lancet, ii, 134.

MOORTHY, V.A. (1983). Minimal change glomerular disease: a paraneoplastic syndrome in two patients with bronchogenic carcinoma. American Journal of Kidney Disease, $3,58$.

NOEL, L.H., ZANETTI, M., DROZ, D. \& BARBANEL, C. (1979). Long term prognosis of idiopathic membranous glomerulonephritis. American Journal of Medicine, 66, 82.

PASCAL, R.R., IANACCONE, P.M., ROLLWAGEN, R.M., HARDING, T.A. \& BENNETT, S.J. (1976). Electron microscopy and immunofluorescence of glomerular immune complex deposits in cancer patients. Cancer Research, 36, 43.

PLAGER, J. \& STUTZMAN, L. (1971). Acute nephrotic syndrome as a manifestation of active Hodgkin's disease. American Journal of Medicine, 50, 56.

REEVES, W.G., CAMERON, J.S., JOHANSSON, S.G.O., OGG, C.S., PETERS, D.K. \& WELLER, R.O. (1975). Seasonal nephrotic syndrome. Clinical Allergy, 5, 121.
RICHARD-MENDES DA COSTA, C., DUPONT, E., HAMERS, H., HOOGHE, R., DUPUIS,E. \& POTVLIEGE, R. (1974). Nephrotic syndrome in bronchogenic carcinoma: report of two cases with immuno-chemical studies. Clinical Nephrology, 2, 245.

ROW, P.G., CAMERON, J.S., TURNER, D.R., EVANS, D.J., WHITE, R.H.R., OGG, S.S., CHANTLER, C. \& BROWN, C.B. (1975). Membranous nephropathy: long term follow up and association with neoplasia. Quarterly Journal of Medicine, 174, 207.

SHALHOUB, R.J. (1974). Pathogenesis of lipoid nephrosis. A disorder of $\mathrm{T}$ cell function. Lancet, ii, 556.

SHERMAN, R.L., SUSIN M., WEKSLER, M.E. \& BECKER, E.L. (1972). Lipoid nephrosis in Hodgkin's disease. American Journal of Medicine, 52, 699.

TU, W.H., PETITTI, D.B., BIAVA, C.G., TULUNAY, D. \& HOPPER, J. (1984). Membranous nephropathy: predictions of terminal renal failure. Nephron, 36, 118.

TYDINGS, A., WEISS, R.R., LIN, J.H., BENNETT, J., \& TEJANI, N. (1978). Renal cell carcinoma and mesangiocapillary glomerulonephritis. New York State Journal of Medicine, 78, 1950.

WAKASHIN, M., WAKASHIN, Y., IESATO, K., VEDA, S., MORI, Y., TSUCHIDA, H., SHIGEMATSU, H. \& OKUDA, $K$. (1980). Association of gastric cancer and nephrotic syndrome: an immunologic study in three patients. Gastroenterology, 78, 749.

WEKSLER, M.E., CAREY, T., DAY, N., SUSIN, M., SHERMAN, R. \& BECKER, C. (1974). Nephrotic syndrome in malignant melanoma: demonstration of melanoma antigen-antibody complexes in kidney. Kidney International, 6, 112A. 